\title{
Use of Smartphone Cameras and Other Applications While Traveling to Sustain Outdoor Cultural Heritage
}

\author{
Ana Slavec *D, Nežka Sajinčič and Vesna Starman \\ InnoRenew CoE, Livade 6, 6310 Izola, Slovenia; nezka.sajincic@innorenew.eu (N.S.); \\ vesna.starman@innorenew.eu (V.S.) \\ * Correspondence: ana.slavec@innorenew.eu
}

Citation: Slavec, A.; Sajinčič, N.; Starman, V. Use of Smartphone

Cameras and Other Applications While Traveling to Sustain Outdoor Cultural Heritage. Sustainability 2021, 13, 7312. https://doi.org/10.3390/ su13137312

Academic Editors: Marek Nowacki and Kristian Fabbri

Received: 23 April 2021

Accepted: 24 June 2021

Published: 30 June 2021

Publisher's Note: MDPI stays neutral with regard to jurisdictional claims in published maps and institutional affiliations.

Copyright: (c) 2021 by the authors. Licensee MDPI, Basel, Switzerland. This article is an open access article distributed under the terms and conditions of the Creative Commons Attribution (CC BY) license (https:// creativecommons.org/licenses/by/ $4.0 /)$.

\begin{abstract}
Outdoor cultural heritage is exposed to several detrimental factors, so involving people in its care can greatly help in its preservation. We conducted four focus groups with participants recruited through a screening questionnaire to find ways of including travelers in a citizen science project by learning about how they interact with monuments through photography, travel apps, and location-based games, as well as their preferences regarding these apps. Since people can be apprehensive about installing new apps, we also verified the potential of games like Geocaching and Pokémon Go for cultural heritage conservation. We found that monuments appear as a photographic motif if they allow for interaction, are part of a photogenic scene or the visitor is attracted to their story. Some use travel apps to get additional information about the sights and discover hidden sites. Since cultural heritage is frequently part of the Pokémon Go and Geocaching gameplay, there is significant potential to use these apps, not only for tourism, but also for citizen science projects involving cultural heritage. While descriptive in nature, these findings provide useful insight into how to combine ubiquitous devices, smart tourism, consumer behavior, and cultural heritage protection for a more sustainable future.
\end{abstract}

Keywords: cultural heritage conservation; citizen science; smart tourism; focus groups; travel photography; visitor applications; location-based games; Pokémon Go; Geocaching

\section{Introduction}

Heritage is important in defining the identity of a society and understanding the past is helpful in addressing its present and future [1,2]. This includes both natural and cultural property, tangible, and intangible culture. In this paper, we focus on built cultural heritage that is tangible and can be both immovable (buildings, archeological sites) and movable (statues). In the outdoor environment, cultural heritage $(\mathrm{CH})$ is exposed to various natural and anthropogenic detrimental factors that contribute to their degradation, such as rain, air pollution, relative humidity, vandalism, etc. (see [3]), which is why regular monitoring is crucial to decrease the risk of losing it. Awareness of this risk has led the scientific and technical community to focus on both the protection and valorization of such heritage $[4,5]$.

One way of protecting $\mathrm{CH}$ is through citizen science projects, in which the lay public contributes by performing scientific work tasks, such as observation, annotation, and classification [6]. In the case of $\mathrm{CH}$, engaging tourists and visitors is especially relevant since they are already interested in the heritage sites, making tourism an ideal tool for supporting $\mathrm{CH}$ conservation [7]. Although $\mathrm{CH}$ tourism is considered one of the oldest forms of tourism, the idea of managing heritage resources as products for tourism consumption is relatively new [8].

Modern information and communication technologies (ICT) offer visitors additional opportunities to interact with $\mathrm{CH}$ sites. According to Google [9], almost three-quarters of users have at least one travel app installed on their smartphone. Moreover, since the end of roaming charges in the EU, travelers are likely to use mobile services when traveling as 
often as they use them at home [10]. Tourism's reliance on ICT is described by the term "smart tourism", with increasing literature addressing its characteristics and interaction with $\mathrm{CH}$ [11]. There is a trend of enhancing experiences for visitors to $\mathrm{CH}$ sites [12,13], such as augmented reality and games that integrate the player's physical location via GPS-enabled devices, such as smartphones, otherwise known as location-based games (LBGs) $[14,15]$.

Given the ubiquitous availability of mobile devices, we could involve visitors of outdoor $\mathrm{CH}$ monuments in the monitoring of those monuments by encouraging them to take photos of any damage, such as corrosion, and submit these photos to the appropriate authorities through a smartphone application. A similar approach in data collection is often used in biology, ecology, and environmental science fields, where citizen science projects are most common and participants are asked to make photographs of, for instance, animal species (e.g., [16-18]). As for heritage care and research, there is one study where the local community was engaged in the monitoring of changes in an archeological site using an app [19], and in another study, crowdsourcing was used to collect visitor photos with the aim to reconstruct a destroyed $\mathrm{CH}$ structure [20]. Moreover, there are examples of utilizing photos generated by visitors to study their experience of coastal and marine areas [21], to understand the meaning of $\mathrm{CH}$ site experiences [22], and another reconstruction of a destroyed $\mathrm{CH}$ structure [23]. However, the visitors were not actively engaged in the projects so we cannot characterize them as examples of citizen science. Nonetheless, there have been attempts to involve citizens in the care of cultural monuments, such as outdoor bronze sculptures, dating back to the pre-smartphone era [24].

This study aimed to understand the use of smartphone cameras, visitor applications, and LBGs while traveling, and the traveler's awareness and perceptions of $\mathrm{CH}$, in order to prepare a strategy for involving target groups in heritage protection. Motivating people to use their mobile devices to help researchers collect data, however, can be a challenge. We conducted focus groups to understand the traveler's motivation to interact with monuments through photography and other smartphone applications. We also focused on users of Geocaching and Pokémon Go LBGs, which already allow such interaction with $\mathrm{CH}$ sites. Three research questions were raised:

1. How are smartphone cameras used while traveling, especially when visiting outdoor $\mathrm{CH}$ ?

2. What are the practices of using smartphone applications when traveling, especially in relation to outdoor $\mathrm{CH}$ ?

3. What is the role of LBGs in promoting the role of outdoor $\mathrm{CH}$ ?

\section{Literature Review}

\subsection{Smartphone Photography While Traveling}

Since the advent of the first built-in mobile phone cameras in the 2000s, this technology has evolved immensely, and contemporary high resolution cameras are replacing compact cameras. Taking photographs is often taken as an inherent part of being a tourist [25], however, research on how and why tourists engage in this behavior used to be scarce, as their photos were usually stored privately and could not be accessed as easily as photographs taken by professional photographers [26]. In this section, we present some studies that identified some patterns. The popularization of social media has boosted sharing photos with different audiences online [27]. Moreover, increasing volumes of data enable the analysis of destination images with computer vision technologies $[28,29]$.

An analysis of a dataset of more than 100 million photos, which the Flickr photo hosting service released in 2014, revealed that there is more outdoor than indoor photography and that nature is more often shown than people and architecture [30]. In contrast, a study of Instagram content showed there are portraits of one or more people [31], however, the analysis did not distinguish between portraits taken indoors and outdoors. When considering $\mathrm{CH}$, both tangible and intangible instances such as crafts, rites, and ceremonies can be photographic motives [32]. Tourists often visit and photograph heritage sites listed by UNESCO, especially those that are large and have been inscribed early [33]. 
In photos taken by tourists, we can distinguish neutral views of landscapes or buildings that do not feature any friends, family, or other people, and those that do [26]. While one study found that faces attract more likes and engagements on Instagram [34], another study that focused on architectural heritage came to the opposite finding, i.e., that images without a human figure receive more likes and comments [35]. Moreover, photos with people often communicate playfulness by pulling faces or standing in ridiculous poses, occasionally interacting with the background, for instance, posing in such a way that it looks as if they are holding a landmark [26,36]. In a way, the posing tourist presents themselves as a desired future memory [37]. Photos of someone who is posing are more likely to be shared online [38].

Two of the main rationales for taking photos were found to be aesthetics and nostalgia [22,39]. Taking aesthetically perfected photos is especially important when they are shared online on Instagram and other social media [30]. While some tourists take conventional shots of buildings and landscapes, others tend to be more creative by trying different angles, using props, or lining up objects in certain ways [26]. Creative photos are more often shared online than those that have a passive approach to photography [38]. In fact, photography is also a practice of identity construction (including historical identity [22]), self-representation, and class identification, by which tourists express themselves and create private meanings and personal narratives [26,36]. However, tourists are often trying to mimic others in taking photos, and some studies found that such photographs tend to replicate iconic images of destinations created by the tourism industry $[25,36,40]$.

As for nostalgia, photographs connect with and revive memories of events, places, and people through memory travel [37], not only personal, but also collective memories [41]. In fact, in some cases, the main consumer of the travel photo is its producer, while in other cases, people engage in the ritual of talking through recent holiday photos with friends or family [26]. The purpose of photos is also to validate the fact that one has visited a destination and, sometimes, photos are put into elaborate albums with accompanying captions and descriptions [26], either in print or in virtual web-based photo albums, that can also be made accessible to more public audiences on social media [30,42]. Another study found that the primary targets of online sharing are co-travelers, especially when they are featured in photos [38]. Photos can also be given as gifts, framed as large prints, and put on walls of living rooms [26]. On the other hand, holiday photographs stay unsorted and are seldom looked at, especially when the frequency of travel is high and traveling is not considered a special event [26].

As we presented in the introduction, there have been some interesting applications of user-generated photos when they have been made publicly available. One of the studies that we referred to in the introduction exposed storytelling and other creative narratives associated with heritage sites as an important motivation for community participation in a citizen science project that included photography [19]. Other than that, we found no explicit mention of stories as a motivation for taking photos.

Finally, it should be noted that studies that rely only on the objective analysis of produced photos offer a limited perspective. To better understand the photos, the subject needs to be asked for the interpretation using in-depth qualitative research methods, such as focus groups and interviews [39]. Focus groups have been previously used to study the motivations for online photo sharing (e.g., [27]) but not in the context of travel and $\mathrm{CH}$.

\subsection{Smartphone Travel Apps}

Smartphones have become omnipresent in our everyday life, but travel has as well [43]. Affordances brought by technological advances have not remained unnoticed by the tourism sector, resulting in the development of smart destinations that try to improve tourists' experiences by using technological infrastructure, such as related websites, social media accounts, applications on mobile devices, augmented and virtual reality (AR, VR), gamification, $\mathrm{QR}$ codes, wearables, and more. 
Research shows that apps can add value and enhance touristic experiences [44-46]. Specifically, smartphone travel apps (STAs) and other smart tourism technologies can promote the exploration of new possibilities, such as discovering new places and the exploitation of existing capabilities for itinerary management [47]. The advantage of mobile applications is that they can adapt to the experience [48], promote interaction between visitors and cultural heritage, between visitors themselves, and between visitors and local people $[46,49,50]$.

Intensive ICT use and looking for a personalized product while traveling is common predominantly among members of generations Y [51-53] and X [54] (born between 1982 and 2002, and between 1961 and 1981, respectively), but not all travel apps are equally well received. Research has, thus, been trying to identify travelers' desires, attitudes, and behaviors to learn what content they find useful, what features they appreciate in smart tourism technology, and their concerns.

In addition to the use of everyday smartphone features for travel, such as the camera, navigation, weather checking, calendar planning, and communicating with others, we also use additional apps that facilitate travel-specific behaviors, such as itinerary management, purposeful information searching, finding things to do, checking reviews, making reservations, transportation tracking, check-in, and finding deals [43]. Interviews with 20- to 25-year-old tourists that are proficient with the use of modern technology revealed that they use mobile devices to seek information to help them make decisions on their trip and they welcome personalized services [55]. Furthermore, a survey-based study on tech-savvy tourism students found that millennials use different mobile technologies during all stages of the trip, especially for receiving information about attractions, proposals for activities, getting discounts, and sharing their experiences with their social networks, but are less willing to interact with destination businesses and services or share sensitive personal data, such as real-time position, to personalize their experience [52]. Similarly, a study on Taiwanese international travelers found that they have a positive attitude towards using smart tourism applications and intend to use them, both prior and during their travels, most commonly to search for information connected to transportation, maps, and points of interest [56].

In addition to their utilitarian value, gamified STAs can provide hedonic attributes such as pleasure. A recent study on factors affecting the adoption of such apps found that the intention to use them was influenced by perceived enjoyment [57-59], but not information quality, and interactions with other users are more important than interaction with game elements. Therefore, good marketing is an important aspect to build a wider app user base [59]. In contrast, a study made on travelers in India reported intention to use STAs is affected the strongest by price-saving orientation, performance expectancy, and social influence, while hedonistic motivation did not significantly predict tourists' intentions to use such apps, implying that although tourism is a hedonistic activity, using STA is not [60]. One study on young adult travelers also revealed that while they appreciate well established technologies for tourism information, such as (multi-language) official destination websites, apps, social media, and free Wi-Fi, they are more skeptical about the potential of smart technologies, such as AR, VR, QR codes, and gamification, to enhance their tourist experiences [52].

Multiple studies showed the importance of privacy and how requiring personal information could hinder the adoption of smart travel apps [47,52,55,59]. Other identified concerns include relying too much on technology, having less interaction with people, getting false information, not experiencing the destination as it is, and abusive marketing [55]. Users want apps they perceive as useful and simple and do not take up too much space in the device $[57,61,62]$. Applications should not require excessive attention to themselves, but encourage interaction with the environment [59], so customization options to prevent continuous service provision are also deemed important [63]. 


\subsection{Playing Location-Based Games While Traveling}

Playing games is an enjoyable and engaging activity in which players voluntarily invest their time and resources, so people have been trying to harness their potential to promote productive outcomes outside of the games [64]. The term "gamification" is being used to refer to the application of game design elements in non-gaming environments to elicit specific attitude or behavior changes [65]. It may range from adding points, badges, and leaderboards to a context outside of a typical game setting to creating whole games that lead to non-game-related outcomes, like finding a destination, taking a photograph, or exercising. [13,66]. As a powerful engagement tool, it has been gaining interest from both researchers and practitioners in several fields, such as marketing and brand attitude [67], consumption [68], technology adoption [59], and education [69]. Furthermore, empirical support also shows its promise in citizen science projects [70] and outdoor $\mathrm{CH}$ learning and management [71]. Due to its economic, social, and environmental benefits, gamification has also been identified as an approach to encourage a more sustainable and smart approach to tourism [72], but research on the use of gamification in touristic experiences, specifically through the lens of technology, is still scarce [13].

Location-based games (LBGs) present an opportunity for combining game elements and tourism to promote further engagement. As the player's location plays a pivotal role and the game directs their users to different places, LBGs can optimize travel routes and support communication between the local community and tourists [72], as well as enhance tourist experiences, engagement, and entertainment [13]. There are many existing LBGs made for visiting specific attractions, cities, or general use, but because people may be apprehensive to download and use new touristic applications or games, especially if they collect personal information like location [59], an already installed app may be a better approach to promote engagement with outdoor $\mathrm{CH}$. Therefore, in our research, we focus on two of the most widely popular LBG examples: Pokémon Go and Geocaching. Even though the COVID-19 pandemic had brought the life of many to a halt, Pokémon Go retained its vast user base, having 58 to 105 million monthly players, on average, from January 2019 to April 2021 [73]. While the Geocaching community is not as big, in 2020 they welcomed 5 million new players and celebrated their 20th anniversary [74].

Geocaching is an outdoor treasure hunt game in which players look for treasures, hidden by other users, based on their location and clues in the smartphone application. Pokémon Go, on the other hand, is an augmented reality game in which players walk around with their GPS-enabled device and interact with creatures known as Pokémon. Both games utilize the users' location and show nearby Pokémon/treasure positions, compelling users to take their smartphones with them, especially in urban areas, so they can play and collect the game's items. While neither game was designed for touristic purposes, by placing points of interest (treasures, Pokémon, PokéGyms, PokéStops, etc.) near $\mathrm{CH}$ sites, natural landmarks, and other touristic attractions, they can guide users and direct their attention to $\mathrm{CH}$.

Although there is some previous research on Pokémon Go and motivation to play, it was based on survey reports, conducted soon after the game's launch in 2016, and did not focus on the tourism context. For example, the main reported motives for starting to play the game were curiosity, being a Pokémon fan, and influence from peers and media, while the most popular reasons for dropping the game were boredom with the situation, difficulties in progressing, and technical problems $[75,76]$. For continuing, some of the reported reasons were progression and finding new or rare Pokémon, exercise outdoors, fun, game enjoyment, nostalgia, being the best, joint activities with family and friends, and escapism [75-79]. In one study, however, three percent of participants noted that one of the reasons for starting to play Pokémon Go was to have a game for traveling [76]. A qualitative study made on Geocachers in the UK also explored their motivations and playing practices [80]. Casual users played mostly during holidays every few months, while regular "cachers" made related trips every weekend or even in the evenings, fitting the game into other parts of their lives and activities, seizing every opportunity to play, such 
as stopping on the way to somewhere on a journey to find a new cache. Main motivations for playing were socializing with family and friends while walking outside, discovering and exploring new places (especially because caches are hidden in interesting or beautiful locations), ongoing collection of treasures, statistics or status in the geocaching community, challenge, and competition [80]. Similarly, a study using four in-depth semi-structured interviews found that in addition to fostering a learning experience, Geocaching players also experience enjoyment and challenge, and view it as a social activity [81]. Furthermore, participants confirmed Geocaching also serves as a motivator to travel and find new attractions. Several apps harness the potential of Geocaching for touristic purposes and offer users self-guided tours and suggestions (see [82]).

While there are studies about using and designing touristic LBGs for specific cities or $\mathrm{CH}$ attractions (e.g., [14,83]), to the authors' knowledge, there is no research specifically focusing on using Pokémon Go, Geocaching, or other popular LBGs with a wide user base in the context of tourism and $\mathrm{CH}$ preservation by citizen engagement.

\section{Methods}

As the use of smartphone photography, games, and other visitor applications in the context of $\mathrm{CH}$ tourism is a topic about which little is known, an exploratory design using focus group interviews was used. Focus groups are a qualitative data collection method in which a moderator leads a group discussion, and since results are interpreted in the context of the group interaction, they are especially useful to study complex behaviors and motivations [84].

We organized four focus groups with smartphone users in two Slovenian cities (Ljubljana and Koper) who made at least one trip in the last year and were not employed as a tourist guide or a market researcher. Both cities have a rich cultural heritage, including several outdoor statues. In both cities, we conducted one focus group discussion with players of LBGs and one with those who do not use such applications.

A mixed method design was used as the selection of participants was carried out based on a screening questionnaire (see Supplement S1) that also included questions about app use, travel behavior, and demographic characteristics. The main aim of the questionnaire was to select candidates to participate in a focus group discussion, but it also served as a tool to get an overview of what smartphone applications are used for travel.

The questionnaire was disseminated in November 2019, mainly by being posted in relevant Facebook groups on the topic of LBGs, travel, and selected cities (see Table A1 in Appendix A), but also through other channels. Based on responses on the first page of the questionnaire, we filtered out those who did not meet the study criteria. Participants that met the criteria were invited to take part in one of four focus groups that took place in the two Slovenian cities from December 2019 to January 2020.

The discussion was based on a pre-prepared list of questions on three content areas: use of the camera on trips and travels, use of other smartphone applications for tourist purposes, and use of LBGs (see Supplement S2), but sub-questions were also asked spontaneously. Each group had one of the co-authors in the role of moderator and the other two as assistants.

Before beginning, participants were given an informed consent form to read and sign. The document described the purpose of the research, the process of selecting participants, risks and benefits, and data processing and storage procedures. It also emphasized voluntary participation, confidentiality, and adherence to the EU's General Data Protection Regulation (GDPR). They were also allowed time to ask questions. Participants were treated with drinks and snacks, and as promised in the invitation, they received a practical gift for participation.

The discussions were recorded, and tapes were transcribed verbatim by two of the co-authors, while the third performed a quality check. Then, each of the co-authors oversaw the coding and analysis for one of the three content sets. Coding the answers was done using the scissor-and-sort technique that consists of identifying which sections of the 
transcript are relevant to the research questions [85]. To ensure objectivity and quality of analysis, all codes for individual sets were thoroughly checked by two other co-authors who suggested appropriate corrections and additions.

The transcripts were anonymized and deposited at the Slovenian Social Science Archive, where they are available to other researchers upon request [86].

\section{Results}

In this section, we first present the results of the screening questionnaire and then the results of the focus group discussion structured around the three research questions.

\subsection{Screening Questionnaire}

The screening questionnaire was active from mid-November 2019 to early January 2020. The link to the survey was clicked by 1421 people, but only 403 of them completed the survey, of which 287 in full and 116 in part. Most of the respondents to the questionnaire came from Facebook groups on trips, excursions, and cities, followed by Pokémon Go and Geocaching, and the least from universities and research institutions, and by invitation received by e-mail.

Out of the 403 participants, 24 were excluded because they did not meet the criteria for participation. The remaining 379 were asked about apps use. As Figure 1 shows, almost everyone used a camera (98\%) and maps (98\%), followed by social networks $(97 \%)$ and travel apps $(65 \%)$, less than half used location games $(47 \%)$. As the majority answered the questionnaire before the end of the year, the percentages for this and further questions may be underestimated.

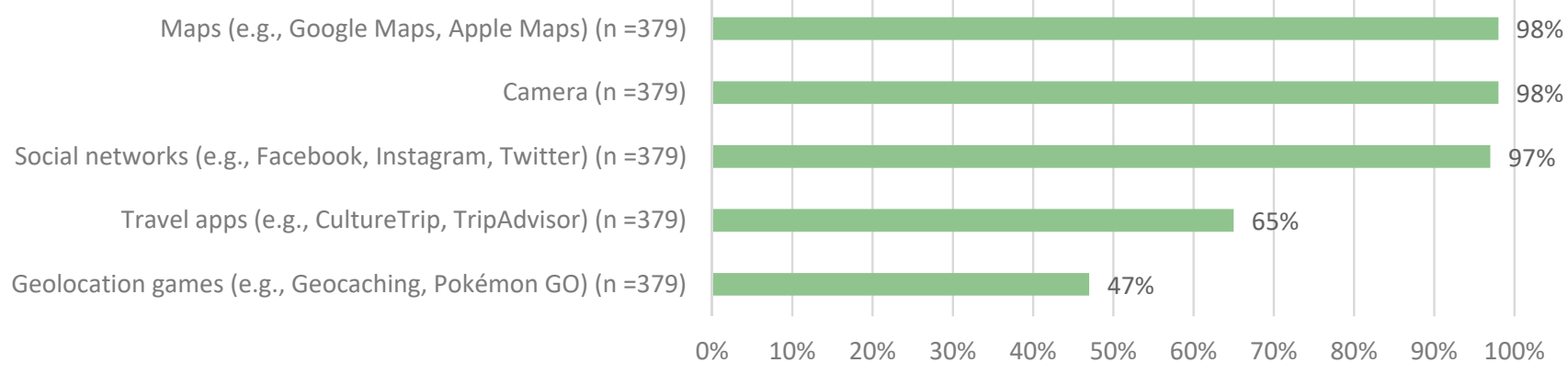

Figure 1. Have you used any of the listed types of applications on your smartphone this year? (Multiple answers possible).

Next, we asked participants about excursions and travels they made in 2019 in Slovenia and abroad. We defined an excursion as short trips without overnight stays to visit a city. Most respondents made at least one trip in Slovenia (95\%) and abroad (87\%), 68\% of respondents traveled with at least one overnight stay in Slovenia, and $92 \%$ of respondents traveled abroad. We eliminated five participants $(1.4 \%)$ who were not on any trip or travel, neither in Slovenia nor abroad. It should be noted that the sample, due to the method of sampling, represents a special group that travels more often than the average resident of Slovenia and, therefore, is not representative of the Slovenian population. For comparison, according to the data from the Statistical Office of the Republic of Slovenia, about $66 \%$ of the Slovenian population aged 15 or older took a private trip in 2019 [87].

Next, we asked participants which of the apps they used in 2019 that they also used on excursions and trips. LBGs were divided into three items: Geocaching, Pokémon Go, and Other. In the end, we offered three more general items second. As the data in Figure 2 show, as many as $98 \%$ of map users also used these on their travels, followed by cameras on a mobile phone $(97 \%)$, social networks $(96 \%)$, and trip applications $(82 \%)$. Among the respondents who played location games (less than half of them are said to be the most popular), Pokémon Go was the most popular, played by $58 \%$ of them on trips, while $33 \%$ of them played Geocaching on trips. 


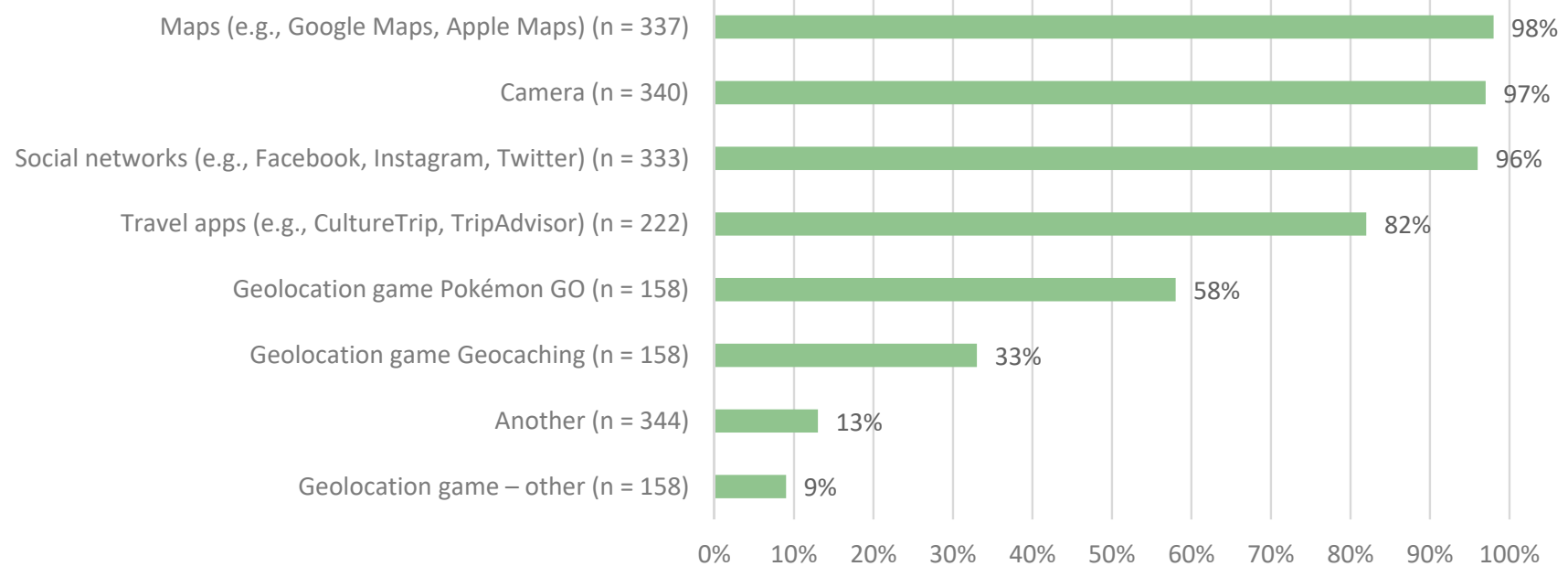

Figure 2. "Which applications did you use on trips and excursions in 2019? (Multiple answers possible)".

As part of the second location game option, participants also listed Ingress (5), Wizards united (4), Munzee (1), c: geo (1), Scanner (1), Worldopo (1), and Harry Potter (1). Among the other applications used by the participants on trips, the answers that appeared most frequently were applications for finding and booking accommodations (27). Transportrelated applications (20) were also frequently mentioned.

Among the 344 respondents who reached the fifth page of the questionnaire, the majority were women (61\%), and according to the age structure, almost half $(47 \%)$ of the participants were younger than 34 . On the next page, 116 participants confirmed that they could participate in the focus group. Those who were willing to attend the event were asked for contact details, and 83 people gave us their name, surname, and e-mail address. 65 also gave us a telephone number.

\subsection{Focus Groups}

As Table 1 shows, we conducted four focus groups with 5 to 7 participants that lasted from an hour and ten minutes (second and third group) to an hour and a half (first and fourth group). A total of 23 individuals participated in all focus groups. Discussions with those who do not play LBGs were about 25 minutes shorter than discussions with LBG players as we asked them fewer questions in the third content set. Although the Koper groups had fewer participants than the Ljubljana groups, they lasted a few minutes longer than the Ljubljana groups.

Table 1. Description of focus groups.

\begin{tabular}{cccccc}
\hline Group & Town & LBG Players & $\begin{array}{c}\text { No. of } \\
\text { Participants }\end{array}$ & $\begin{array}{c}\text { Discussion Duration } \\
\text { (h: min: s) }\end{array}$ & $\begin{array}{c}\text { No. of Lines } \\
\text { of Transcript }\end{array}$ \\
\hline 1 & \multirow{2}{*}{ Ljubljana } & Yes & 7 & $1: 35: 21$ & 998 \\
2 & No & 6 & $1: 07: 47$ & 874 \\
\hline 3 & \multirow{2}{*}{ Koper } & No & 5 & $1: 09: 09$ & 851 \\
4 & & Yes & 5 & $1: 33: 58$ & 1098 \\
\hline
\end{tabular}

Although we tried to have gender and age balance in each of the four groups, we were able to achieve that only in the first group, while for other groups, the number of available participants with required characteristics was not sufficient and many canceled at the last minute. The fourth group was predominately male, the second predominantly female, and the third exclusively female with less age variability than the other three groups. In terms of travel, the two Ljubljana groups had people with more trips and excursions than the two Koper groups. Characteristics of focus group participants (using pseudonyms) are 
presented in Table A2 in Appendix A, and an overview of their responses in spreadsheet format is given in Supplement S3.

In the following subsections, we present the results of focus groups for each of the research questions. The results are graphically presented in the form of three mind maps (see Supplements S4-S6).

\subsubsection{Smartphone Photography While Traveling}

Two participants in one of the focus groups said that they use the camera all the time when they travel, while two participants in one of the other groups reported that they use it rarely or less than they used to. Four participants in different focus groups described how the camera is already useful in the trip preparation phase to store important information, as well as during the trip for practical purposes such as automatic translation, documentation of vehicle damage, and marking the route or location.

On the trip, participants use the camera to photograph "spontaneous things" (1), everything interesting (2) and, above all, to catch memories (5), as well as to prove that they have been somewhere (1). Sometimes the purpose of photography is also to post it online (4), and one of the participants mentioned the use of advanced camera features when taking photos.

The motif of photography is dominated by nature (12) and people (11), but architecture (9), landscapes (7), and tourist attractions (6) were often mentioned. Regarding $\mathrm{CH}$, the most frequently mentioned were buildings (9), especially older ones, and some also mentioned statues (5). Others commented that they do not take photos of buildings and statues by themselves but are only interested in them if there is an interaction of the statue with nature and/or people (4). Examples of intangible heritage, such as parades and other events, were mentioned by only two participants. One participant stated that she is particularly interested in visiting UNESCO heritage sites. Moreover, some participants noticed that they perceive $\mathrm{CH}$ earlier and take pictures with it if they are abroad (4). They are less susceptible to perceiving it in their home country, but they also noted some exceptions to the rule.

As already mentioned, interaction with the statue is an important motive for photography (7), both in the context of smartphone games and outside them. Both children and adults pose next to statues. The most popular are statues that you can climb on or touch for good luck. Some participants use the camera as part of games, for example, to photograph found treasures. In addition to the possibility of interaction, important motifs for photographing statues are also aesthetics, location of the statue, and what it represents.

Many participants agreed that what matters is the story (9) of what the statue symbolizes and what it expresses. Some also mentioned reading about the statue before visiting (3), while several photograph the inscription on the $\mathrm{CH}$ monument or the information board next to it and read it later (4).

People rarely pay attention to the material from which the statue is made, only if it is something special. Most noticed are a statue's flaws and wear, which some find as an interesting photographic motif (2).

Some participants told us they keep the pictures only digitally (4), while some print at least some to show to family and friends (9), sometimes even as gifts. One participant reported that he only looks at the photos himself and rarely shows them to anyone. Several participants upload images online, some on a smaller scale, others on a larger scale. Online, some share them only privately in closed groups of friends and acquaintances (8), some in closed groups that include strangers (1), or even publicly (4). While one participant was motivated by posting photos on Facebook to share them with co-travelers that are in the photo, the participants who use closed groups shared them with family members and/or co-workers that stayed at home. One of the participants that posted photos on social media pointed out the purpose of posting is to show off her vacation photos to everyone else. The participant who posted photos in closed groups with strangers explained that she is attempting to promote Slovenia with her posts. 


\subsubsection{Smartphone Travel Apps}

The most popular travel-related apps among our focus group participants were Tripadvisor, and apps for navigation and public transportation, such as Maps to Go (1), HERE WeGo (1), Uber (1), and Google Maps (4). Participants also mentioned tourismspecific apps that provide information about the sights in a local environment, namely Slovenia Trails (1), Atlas Obscura (1), and Secret Travel (1).

When participants were asked about apps they liked and found useful, three of them described a local gamified application intended for elementary school students. The app guides them from point to point, where users receive points or badges after correctly answering questions. One participant mentioned Slovenian application Nexto, that harnesses the power of augmented reality as a prize. Not tied to a specific place, the story guides visitors from point to point, offers quizzes, and narrates historical data. After collecting a specific number of points, the app generates an AR character, such as a boat on a body of water.

Next, we asked the participants about features that influence their decision to download, use, ignore, or delete a travel-related application and what kind of travel/tourismrelated app they would prefer. The listed characteristics can be grouped into two categories: content and usability.

Regarding content and the app's purpose, most participants expressed the importance of enhancing or adding to the original experience. Most would want a guide that suggests (themed) routes/tours, provides them with additional information about the sights and cultural heritage, helps them discover hidden sites and feel the "city pulse", or offers organizational assistance by estimating the time between each point of interest (1). The most highlighted contribution of the app was fun (5). For example, all participants agreed that they are motivated and attracted by stories. They stressed that the information in the stories must be based on a credible source, but it must be interesting and contain unknown details or be written in a witty way (2). On the other hand, one participant mentioned travel apps as games. When discussing preferences for a touristic LBG, participants expressed that the app should be interactive (1) and include interesting challenges, such as asking questions about exhibitions (1) or solving puzzles at each point (1), however, the tasks should not be too difficult (1).

Concerning usability and technical aspects of travel apps, participants stressed the app's perceived ease of use, starting at its installation (2). Another critical feature is the coverage of the app. It should be relevant as widely as possible, ideally worldwide or at least for a country or bigger city, and not limited to a small location (2). Some also pointed out the significance of providing information about exhibitions in multiple languages (2) and offering different options (1). In addition, app users are really bothered by maps being inaccurate, forcing them to constantly switch between the app in question and a navigation app (1). The app should be designed in a way that allows immersion in the real environment and not constantly demand the users' attention by looking at their device (2). Some expressed the importance of harnessing the opportunities of 5G technology (1), but for others, especially LBGs users, limited battery life and data roaming can be an issue (4), so being able to use the app offline and connect to Wikipedia to read more about the destination is a great benefit (1). Limited smartphone storage space is also of importance, so the app should not take up a big portion of space (2). One participant suggested that the app, or additional features such as $3 \mathrm{D}$ views and sound clips, could be activated when scanning a QR code, but participants in two groups were not convinced (2), one commenting QR code scanning is outdated technology. Other suggestions included utilizing the power of AR and VR to exhibit additional information about sights, such as how a monument looked like through time, display a military battle on the spot, or statues coming to life and telling their story (2). Finally, a crucial issue was the marketing aspect. One participant commented that they would first have to know about the app's existence, which many times is not the case, even if they would download and use the app. 
When discussing a potential gamified STA that would also allow visitors to send photos of the current state of outdoor cultural heritage, as part of a citizen science project, three participants replied they would participate. They suggested taking advantage of AR options, such as showing a character representing a landmark (2) or dressing up a statue (2). They would be interested in collaboration if they learned something new at the same time (2) and to help science (2). Other participants would need additional motivation, for example, in the form of promotional activities (1) and entertainment (1). The activity should not take too long (2), the instructions should be short and concise (4) and represent a broader context (1). When asked about the motivation for using such an app, some participants replied that their biggest motivation would be to help protect cultural heritage or science, while others would be motivated by prizes, such as souvenirs (3), vouchers (4), or a discount for experiences (16) or food (4). However, two emphasized that they would be bothered if their tasks would be exploited for commercial purposes. Finally, most participants (6) would not post the photos on social media but would send them to researchers directly through the app (6). The added value would be a database or web album where photos would be uploaded and to which participants would have access.

\subsubsection{Playing Location-Based Games While Traveling}

This section contains information mostly from the 11 respondents who participated in the LBG user focus groups, of whom 5 use Geocaching and 5 Pokémon Go. While participants from the other two focus groups have never used Pokémon Go, they are familiar with it but have a negative attitude towards it. On the other hand, most of them have never heard of Geocaching or other LBGs.

The most reported reason to start using LBGs was getting a recommendation from others (5), but some participants also mentioned the opportunity to motivate children (2), visit new places and find new, interesting locations (3), increase physical activity (1), interest in hidden treasures and challenges (3) and, in the case of Pokémon Go, nostalgia (1). Most of the participants have been using the LBGs for multiple years (10), with some downloading the Pokémon Go app as soon as it was possible (3), one even buying a more powerful smartphone to be able to play.

Most of the participants are casual players, some use the app more regularly, but almost all use the app at least a little in new places, even on longer trips. Regular players are also willing to cover some of the costs associated with the game (e.g., purchase of equipment, mobile data, upgrades) while others are not.

Some users play mostly alone (2), while others play with friends (2) or their family, often as part of family trips (7). Two participants reported their children eventually lost interest in the games, while they remained enthusiastic. Participants who play with friends mentioned that while their company joins them while playing, their friends do not play on their own and they do not have the app installed on their phones.

The most important motives for playing are socializing and interacting with other players, both in the virtual and physical environment, cooperation, and a sense of belonging to the community (9), which extends over local borders. Several respondents mentioned they met new people abroad through the game, and two even participated in international mass events related to the apps. Another important factor for long-term usage of these LBGs is enjoyment while performing the actual tasks, such as finding treasures, solving puzzles, as well as learning about new places and stories (6), but also constant emergence of novelty inside the app (3), otherwise players get tired.

LBGs should be simple. The results should be kept permanently and the treasures should be well maintained, otherwise players give up on the game. It is also essential for users to have many different options for setting challenges and achieving goals, which they do in different ways. The feeling of achievement can be attained through collecting limited or rare objects, such as badges that are tied to a specific behavior or Pokémon that are only available in certain locations. 
Moreover, LBGs offer users ideas for trips (3) and act as tour guides that take players around a city (1) and provide them with interesting information about the sights (3). Several users reported they have visited places and seen things they otherwise would not without these kinds of games, as local sights and statues are often part of LBGs, e.g., in the form of PokéStops, Gyms, or virtual treasures, and include photography, both because of the sights themselves and because the task requires users to prove that they were at a particular location. GeoTour, a form of collaboration between Geocaching and tourist associations or companies, was also mentioned by the group, so there are multiple possibilities of cooperation between the tourism sector and LBG users. Multiple participants (7) also pointed out that LBGs play a part in deciding where to go in case of local trips and the micro-location of their travels abroad.

\section{Discussion}

In this section, we discuss results and compare them to previous studies for each of the three research questions: smartphone photography, travel apps, and playing LBGs.

\subsection{Smartphone Photography While Traveling}

For some participants in our study, photography is an inherent part of being a tourist, as was indicated in previous research [25], while others take photos less often than they used to. The latter might be explained by the fact that these participants are frequent travelers who, according to previous studies, tend to look at photos less often [26].

While the literature on travel photography of $\mathrm{CH}$ is scarce, it was mentioned by our participants a couple of times, but less often than nature and people, which is in line with findings of the study that found nature as the prevailing motif in Flickr photos [30] and also another study that found almost half of the photos on Instagram are portraits of people [31]. Most of the $\mathrm{CH}$ mentions by our focus group participants were about tangible heritage, such as buildings, and there were only two mentions of intangible heritage. One of the participants told about often choosing to visit UNESCO sites, which is also something that was found in the literature [33]. Focus group discussions confirmed that it is a sensible decision to conduct them with people who travel, as a few participants mentioned that they only rarely pay attention to and take photos of $\mathrm{CH}$ and their local environments, which is also in line with literature that stresses the role of tourism in preserving and enhancing built $\mathrm{CH}$ (e.g., [7]).

Among our participants, there were both those who take neutral shots of buildings and landscapes without any people and those who are only interested in taking photos if there is an interaction of the motif with people, which also matches previous research. While the latter described interactions that included posing behaviors such as pulling faces and taking ridiculous poses [26], in our study, participants mostly mentioned climbing or sitting on statues or touching them for good luck.

Aesthetics and nostalgia that were identified as two main motifs for taking photos in previous studies [39] and were also indicated by our participants. In addition to specifically mentioning collecting memories, the latter was perceived in the statement that photos are proof that they have traveled somewhere, which was also mentioned in previous studies [26]. As for aesthetics, participants in our study stressed the importance of colors and having an eye for interesting details, wherein even flaws and wear can be interesting photographic motifs.

According to both previous studies and our research, there are tourists that only store photos digitally and those who print them to show to family and friends, including printing them as gifts [26]. The use of albums was mentioned in our study but without indication of the use of captions and descriptions. Some of our participants also upload the photos to social media and, in that case, aesthetics is even more important, as was also found in the literature [30,42]. One participant said co-travelers were the main target of photo sharing on social media, as indicated in one of the previous studies [38], while some of our other participants said they share them with those who stayed at home. 
Since our study used active data collection with focus groups instead of relying only on the passive analysis of photographic outputs [39], our analysis enabled us to find patterns of use that we did not see reported in previous literature. First, the usefulness of the camera in the trip preparation phase for various practical tasks. Second, according to our participants who know monument stories, what monuments symbolize and express is an important motivation for visiting $\mathrm{CH}$ sites. Except for one study [19], there were no mentions of the importance of storytelling. Third, $\mathrm{CH}$ is perceived more frequently when traveling abroad compared to domestic travel. Finally, some participants use the camera for games, which we explored more thoroughly within the two other research questions.

On the other hand, except for one participant that said she posted vacation photos to show off her vacations, among our participants there was no awareness of some of the aspects mentioned in previous literature, such as identity construction, self-representation, and class identification, by which tourists express themselves and create private meanings and personal narratives [26]. Our participants also did not mention mimicking other tourists or professionals when taking pictures, as was the case in some of the previous studies $[25,40]$.

\subsection{Smartphone Travel Apps}

Since the literature gathered evidence on how STAs can enhance touristic experiences (e.g., [44-46,49,50]), we asked focus group participants about their relationship with STAs and what features they deem important when making decisions about their use. Our findings mostly replicate those of previous studies and the discussed features can be grouped into two categories: content or purpose of the apps, and their usability. Participants described using their smartphones both before and during their trips, mainly searching for information about sites and itinerary management, such as transport-related information, maps, and attractions $[43,52,55]$.

Previous research on tech-savvy young adults has shown mainly positive attitudes toward STAs [56], but with a preference to more established technologies for tourism information, such as destination websites, apps, and social media, they were less inclined to like more advanced technologies or local apps for interacting with destination businesses and services [52]. Our respondents, however, had varied attitudes towards STAs. While some expressed great interest in smart technologies like AR, VR, QR codes, and gamification, their intention to use and actual past behavior differed from their suggestions, as only a small fraction of them have already used such apps and downloaded a local STA, which can be partly attributed to differences in samples, as ours included travelers of different ages and backgrounds.

While discussing a potential local gamified STA that would also serve as a citizen science project to protect outdoor cultural heritage, participants emphasized the importance of enriching experiences and adapting experiences to the individual $[43-46,48]$. The app should be interactive [48] and facilitate interaction between visitors and cultural heritage, between visitors themselves, and between visitors and local people $[46,49,50]$. Participants put strong emphasis on hedonistic features, like fun and enjoyment, both through games and witty stories. While some studies highlighted the importance of perceived enjoyment and interacting with other app users [57-59], another reported hedonistic motivation did not predict intention to use STA, with price-saving, performance expectancy, and social influence being the strongest factors [60]. Although our participants mentioned all these criteria, as mentioned, actual use of such apps was low and only three mentioned they would use an app like this in the future, showing a disparity between interest, intention, and behavior, supporting the notion that although tourism is a hedonistic activity, using STA is mainly utilitarian in nature [60]. Furthermore, the intention of using this potential app mainly came from wanting to help science and cultural heritage protection, not the gamified part in itself, as participants mentioned they would want to learn something from such an app. 
Finally, usability and technical aspects were an important factor when discussing STAs, both existing and hypothetical, replicating findings from other studies [57-59,61-63]. Participants emphasized multiple times that, in addition to apps being useful, they should be simple and easy to use and install. An important feature is the coverage with the application-its scope should be as wide as possible, preferably worldwide or at least covering a country or a larger city and should not be limited to a small location. Some also pointed to the importance of providing information on exhibitions in several languages and offering different options to enable customization $[43,63]$. Especially for LBGs users, limited battery life and data roaming can be a problem, so using the app offline and connecting to Wikipedia is a big advantage. Limited storage space on a smartphone is also important, so the app should not take up a lot of space.

Several concerns about STAs raised during discussion replicated those in past studies, such as not wanting technology to demand too much of their attention so they can interact with people and experience their environment in full, obtaining inaccurate information, and exploiting their activity for commercial purposes [55]. The biggest issue, however, was privacy, especially sharing personal data for personalization purposes. Much research has identified this as an important concern for travelers, but smart destinations developing local STAs to enhance their experience see this as a concern as well. Personal information is needed to personalize the app, but requiring the sharing of sensitive data lowers the possibility of app adoption $[47,52,55,59]$.

\subsection{Playing LGBs While Traveling}

Due to people's apprehension to download new location-specific applications [59], we verified the potential of utilizing well-known games that some have already installed to facilitate heritage conservation. While this strategy excludes non-users of such apps, especially since they seem to have strong negative attitudes towards them, these popular games have still a wide and motivated user base [73,74].

In line with findings in previous literature, our respondents reported that they started using these apps based on their friends' recommendations, nostalgia, and to spend more time outdoors being physically active and socializing with friends and family [75,76]. In contrast to those studies, however, focus group participants had finding and visiting interesting new locations and their interest in hidden treasures and challenges in mind even before downloading the apps, while those reasons were listed as motives to continue to play in quantitative studies. Only a small fraction of participants in one study listed having a game for traveling as a reason to start playing Pokémon Go [76]. This discrepancy can be a result of different study objectives, methods, and populations. While our qualitative research focused on a small sample of travelers who use Pokémon Go and Geocaching, the mentioned literature included a higher number of players in general who filled out questionnaires. Another reason can be that people do not differentiate between reasons for starting and continuing to play, and if not being specifically asked to be precise, they report them interchangeably.

Besides these slight differences, reasons for continuing to play were consistent with previous literature on both Pokémon Go and Geocaching [75-81]. There is a strong social component to those games since being part of a community and socializing with other players, family, and friends were the most common referred motives for playing in our group, even though some play mostly alone. Several reported meeting people abroad and participating in international mass events based on the games, further solidifying the apps potential for travel use by utilizing the players' enjoyment while performing gameplay tasks. Next, users are motivated to play the games while traveling or being abroad since by collecting treasures in different countries, they can obtain certain rewards like badges or get objects that are rare, new, or available only in specific locations. Finding new places and learning information about specific sites was also mentioned as a strong benefit of the game and motivated users to both play the game and travel more [81]. 
Our research fills the literature gap of investigating the role of gamified smartphone applications in tourism and cultural heritage protection [13,71,72], and shows the potential of using already installed LBGs as an engaging and motivating tool to promote both visitation and interaction with outdoor monuments. On one hand, even though neither LBG was made for a touristic or educational purpose, several participants noted that they provide the users with new ideas for trips and present interesting information about the sights, so they can act as a local tour guide. In this way, LBGs can influence the location of travelers' trips. On the other hand, Geocaching users already occasionally send photos of their location as part of the game, so involving them in citizen science projects for collecting pictorial information about the current state of bronze monuments seems feasible. Pokémon Go also includes options to take photographs inside the app but sending photographs to others is not part of the gameplay in the way it is in Geocaching. As built-in photography and sharing options can facilitate those actions and both apps seem to already lead players to natural and cultural heritage sites, Pokémon Go and Geocaching seem to be feasible candidates for including the lay public in heritage conservation projects by sending pictures.

\section{Conclusions}

By conducting a screening questionnaire and focus groups, we obtained answers to research questions on the use of smartphone applications on excursions and trips in connection with $\mathrm{CH}$ monuments. Regarding photography, we found that monuments appear as a photographic motif if they allow interaction and/or are part of a photogenic scene and/or the visitor is attracted to their story, otherwise this motif occurs less frequently. In addition to the camera, some use other STAs, but they prefer those that do not demand too much of their attention. We also gained insight into how LBGs, especially Pokémon Go and Geocaching, can be useful in promoting $\mathrm{CH}$ sites.

Along with answering the questions discussed, we came to other interesting findings on the use of travel applications and related topics that will make the results widely useful in the development of tourism applications for $\mathrm{CH}$ promotion beyond the present project. The focus groups' results can help develop social mechanisms for involving the public in $\mathrm{CH}$ preservation in the form of games to increase the interaction of visitors with $\mathrm{CH}$ and promote it on social media. The increased public interest in the preservation of $\mathrm{CH}$ can help improve its sustainability. For instance, a database of photos uploaded by visitors can be used for analysis with computer vision techniques to detect corrosion and other defects in monuments. Moreover, it could be used to identify what is considered a defect by visitors.

It should be noted that the methodological approach we used has certain limitations. The screening questionnaire used non-probability convenience samplings, and given the selection of Facebook pages, it is biased towards people who travel more than the general population. This issue is even more pronounced in the qualitative part of the research. However, the purpose of qualitative research is not to make statistical generalizations of the findings but to obtain an in-depth look at the problem. Our study is explorative in nature, and its findings can serve as a starting point for further studies on the topic. For instance, there are additional quantitative research approaches such as content analysis of usergenerated content published online that could be used to study these research questions and compare them with our results. First, an analysis of a sample of publicly available photos could be used to identify a series of their characteristics. Second, an analysis of visitors reviews of monuments and of user reviews of travel apps and location-based games could provide additional insight into their likes and preferences.

Moreover, our study is limited to only one country. One of the further research directions could be a comparative study that would cover different countries and cultures. Within such a study an interesting aspect would be also political attitudes and values in relation to $\mathrm{CH}$ monuments, including attitudes towards attempts to remove or destroy $\mathrm{CH}$ due to political motivations. 
Another limitation of our study is the outbreak of the COVID-19 pandemic, which probably had a significant impact on travel decisions and behavior. It would be interesting to explore the changes in interaction with monuments. On the other hand, the pandemic may also result in less use of traditional tourism products, which involve a lot of contact between people. We wonder if this will make it more common for tourists to use mobile games and other applications and take refuge in the virtual world, which would present an opportunity for visitor app developers. This is a question that could be addressed in future research.

Supplementary Materials: The following are available online at https: / www.mdpi.com/article/ 10.3390/su13137312/s1, Document S1: Screening questionnaire, Document S2: List of questions for focus groups, Document S3: Overview of responses, Document S4: The use of smartphone photography while traveling (mind map), Document S5: The use of smartphone visitor apps (mind map), Document S6: The use of location-based games (mind map).

Author Contributions: All authors participated in the conceptualization, data collection, and writing of the article. The transcripts were prepared by the second and third authors, while data curation and visualization was the domain of the first author. All authors have read and agreed to the published version of the manuscript.

Funding: The authors gratefully acknowledge the European Commission for funding the InnoRenew project (grant agreement \#739574) under the Horizon2020 Widespread-Teaming program and the Republic of Slovenia for funds from the European Regional Development Fund. The authors also acknowledge the financial support of the Slovenian Research Agency for funding the projects Protection of bronze monuments in the changing environment (J7-9404) and Using questionnaires to measure attitudes and behaviors of buildings users (Z5-1879).

Institutional Review Board Statement: Ethical review and approval were waived for this study as it did not include any ethical issues.

Informed Consent Statement: Informed consent was obtained from all subjects involved in the study.

Data Availability Statement: The data from the screening questionnaire and focus group transcript are available via the Slovenian Social Science Data Archive [86].

Acknowledgments: Authors would like to thank project partners at the Institute for the Protection of Cultural Heritage of Slovenia and the Slovenian National Building and Civil Engineering Institute, as well as colleagues at InnoRenew $\mathrm{CoE}$, for providing input and feedback for the design of the study. In particular, we thank our colleague Liz Dickinson for language editing. Finally, thanks to respondents who took the time to fill out our survey. Among them, a special thanks goes to the 23 focus group participants for providing valuable insights and suggestions about the research topic.

Conflicts of Interest: The authors declare no conflict of interest. The funders had no role in the design of the study; in the collection, analyses, or interpretation of data; in the writing of the manuscript; or in the decision to publish the results.

\section{Appendix A}

Table A1. Facebook groups where a link to the screening questionnaire was posted, sorted by number of members.

\begin{tabular}{ccc}
\hline Original Group Name & Group Name Translation & No. of Members on 20 November 2019 \\
\hline Potovanja so moja ljubezen & Traveling is my love & 15,225 \\
Potujem poceni & I travel cheap & 12,898 \\
Ljubljana & Ljubljana & 7579 \\
Univerza v Ljubljani & University of Ljubljana & 4539 \\
Poceni potovanja in izleti & Cheap trips and excursions & 4424 \\
Potovanja (informacije, nasveti, & Travel (information, tips, & 3631 \\
vprašanja) - popotniki za popotnike & questions) - travelers for travelers & 3251 \\
Pokémon GO Slovenija & Pokémon GO Slovenia & 1223 \\
Potovanja \& počitnice z otroki & Travel \& holidays with children & 902 \\
Piran danes & Piran today &
\end{tabular}


Table A1. Cont.

\begin{tabular}{ccc}
\hline Original Group Name & Group Name Translation & No. of Members on 20 November 2019 \\
\hline Pokémon GO Kongresc & Pokémon GO Congress square & 829 \\
Geocaching Slovenija & Geocaching Slovenia & 633 \\
Pokémon GO Koper & Pokémon GO Koper & 117 \\
Visit Piran & Visit Piran & 105 \\
\hline
\end{tabular}

Table A2. Description of focus group participants.

\begin{tabular}{|c|c|c|c|c|c|c|c|}
\hline Group & $\begin{array}{l}\text { Pseudonym } \\
\text { in Transcript }\end{array}$ & $\begin{array}{c}\text { No. of } \\
\text { Excursions } \\
\text { in Slovenia }\end{array}$ & $\begin{array}{l}\text { No. of } \\
\text { Excursions } \\
\text { Abroad }\end{array}$ & $\begin{array}{l}\text { No. of Trips } \\
\text { in Slovenia }\end{array}$ & $\begin{array}{c}\text { No. of Trips } \\
\text { Abroad }\end{array}$ & Gender & Age \\
\hline \multirow{7}{*}{1} & Amanda & 10 or more & 10 or more & $2-5$ & 10 or more & Female & $45-54$ \\
\hline & Brina & 10 or more & 6-9 & $2-5$ & 6-9 & Female & $25-34$ \\
\hline & Ciril & 2-5 & 1 & $2-5$ & $2-5$ & Male & $25-34$ \\
\hline & Črt & 10 or more & $6-9$ & $2-5$ & $2-5$ & Male & $45-54$ \\
\hline & Dragan & 6-9 & $2-5$ & $2-5$ & $2-5$ & Male & $35-44$ \\
\hline & Eva & 10 or more & $2-5$ & 6-9 & $6-9$ & Female & $18-24$ \\
\hline & Filip & 10 or more & $6-9$ & 10 or more & $6-9$ & Male & $18-24$ \\
\hline \multirow{6}{*}{2} & Greta & $2-5$ & 10 or more & $2-5$ & 10 or more & Female & $45-54$ \\
\hline & Hana & 1 & 1 & 0 & 6-9 & Female & $25-34$ \\
\hline & Irena & $2-5$ & 1 & $2-5$ & $2-5$ & Female & $55-64$ \\
\hline & Jasna & 2-5 & $2-5$ & 1 & 2-5 & Female & $45-54$ \\
\hline & Katica & 10 or more & 1 & 0 & 10 or more & Female & $35-44$ \\
\hline & Lovro & 10 or more & 10 or more & $2-5$ & 10 or more & Male & $25-34$ \\
\hline \multirow{5}{*}{3} & Nastja & $6-9$ & $2-5$ & 1 & $2-5$ & Female & $25-34$ \\
\hline & Olga & $2-5$ & $2-5$ & $2-5$ & 1 & Female & $45-54$ \\
\hline & Pia & $2-5$ & 1 & 0 & $2-5$ & Female & $35-44$ \\
\hline & Rebeka & 1 & 0 & 0 & $2-5$ & Female & $35-44$ \\
\hline & Simona & $2-5$ & $2-5$ & $2-5$ & $2-5$ & Female & $35-44$ \\
\hline \multirow{5}{*}{4} & Tadej & 6-9 & $2-5$ & $2-5$ & $6-9$ & Male & $25-34$ \\
\hline & Urban & 10 or more & $2-5$ & 1 & $2-5$ & Male & $18-24$ \\
\hline & Vasja & 2-5 & 1 & 0 & 1 & Male & $18-24$ \\
\hline & Zoran & 10 or more & $6-9$ & 1 & $2-5$ & Male & $45-54$ \\
\hline & Živa & 2-5 & 1 & $2-5$ & $2-5$ & Female & $25-34$ \\
\hline
\end{tabular}

\section{References}

1. ICCROM; ICOMOS; IUCN; UNESCO World Heritage Centre. Managing Cultural World Heritage; United Nations Educational, Scientific and Cultural Organization: Paris, France, 2013.

2. O'Keefe, R. The 1999 Second Hague Protocol. In The Protection of Cultural Property in Armed Conflict; Cambridge University Press: Cambridge, UK, 2009; pp. 236-301.

3. UNESCO World Heritage Centre. List of Factors Affecting the Properties. Available online: https://whc.unesco.org/en/factors/ (accessed on 9 April 2021).

4. Maietti, F.; Piaia, E.; Turilazzi, B. Digital documentation: Sustainable strategies for cultural heritage assessment and inspection. In Proceedings of the SBE 16 Malta, Europe and the Mediterranean Towards a Sustainable Built Environment Conference, Valletta, Malta, 16-18 March 2016; pp. 303-308.

5. Moropoulou, A.; Labropoulos, K.C.; Delegou, E.T.; Karoglou, M.; Bakolas, A. Non-destructive techniques as a tool for the protection of built cultural heritage. Constr. Build. Mater. 2013, 48, 1222-1239. [CrossRef]

6. Wiggins, A.; Crowston, K. From conservation to crowdsourcing: A typology of citizen science. In Proceedings of the 44th Hawaii International Conference on System Sciences, Kauai, HI, USA, 4-7 January 2011; pp. 1-10.

7. Ismagilova, G.; Safiullin, L.; Gafurov, I. Using historical heritage as a factor in tourism development. Procedia Soc. Behav. Sci. 2015, 188, 157-162. [CrossRef]

8. McKercher, B.; Ho, P.S.Y. Assessing the tourism potential of smaller cultural and heritage attractions. J. Sustain. Tour. 2006, 14, 473-488. [CrossRef]

9. Google. How People Use Their Phones for Travel. 2016. Available online: https://www.thinkwithgoogle.com/marketingstrategies/app-and-mobile/smartphone-for-travel-usage-statistics/ (accessed on 12 April 2021). 
10. Eurobarometer. The End of Roaming Charges within the EU. 2017. Available online: https:/ / europa.eu/eurobarometer/surveys/ detail/2178 (accessed on 1 June 2021).

11. Kontogianni, A.; Alepis, E. Smart tourism: State of the art and literature review for the last six years. Array 2020, 6, 100020. [CrossRef]

12. Cirulis, A.; De Paolis, L.T.; Tutberidze, M. Virtualization of digitalized cultural heritage and use case scenario modeling for sustainability promotion of national identity. Procedia Comput. Sci. 2015, 77, 199-206. [CrossRef]

13. Xu, F.; Buhalis, D.; Weber, J. Serious games and the gamification of tourism. Tour. Manag. 2017, 60, 244-256. [CrossRef]

14. Maia, L.F.; Nolêto, C.; Lima, M.; Ferreira, C.; Marinho, C.; Viana, W.; Trinta, F. LAGARTO: A LocAtion based Games AuthoRing TOol enhanced with augmented reality features. Entertain. Comput. 2017, 22, 3-13. [CrossRef]

15. Leorke, D. A definition and brief history of location-based games (2001-08). In Location-Based Gaming; Palgrave Macmillan: Singapore, 2019; pp. 17-44.

16. Araujo, G.; Snow, S.; So, C.L.; Labaja, J.; Murray, R.; Colucci, A.; Ponzo, A. Population structure, residency patterns and movements of whale sharks in Southern Leyte, Philippines: Results from dedicated photo-ID and citizen science. Aquat. Conserv. Mar. Freshw. Ecosyst. 2017, 27, 237-252. [CrossRef]

17. Smith, A.M.; Ramsay, P.M. A comparison of ground-based methods for obtaining large-scale, high-resolution data on the spring leaf phenology of temperate tree species. Int. J. Biometeorol. 2020, 64, 521-531. [CrossRef]

18. Tiralongo, F.; Crocetta, F.; Riginella, E.; Lillo, A.O.; Tondo, E.; Macali, A.; Mancini, E.; Russo, F.; Coco, S.; Paolillo, G.; et al. Snapshot of rare, exotic and overlooked fish species in the Italian seas: A citizen science survey. J. Sea Res. 2020, 164, 101930. [CrossRef]

19. Karl, R.; Roberts, J.; Wilson, A.; Möller, K.; Miles, H.; Edwards, B.; Tiddeman, B.; Labrosse, F.; La Trobe-Bateman, E. Picture this! Community-led production of alternative views of the heritage of Gwynedd. J. Community Archaeol. Herit. 2014, 1, 23-36. [CrossRef]

20. Vincent, M.L.; Gutierrez, M.F.; Coughenour, C.; Manuel, V.; Bendicho, L.-M.; Remondino, F.; Fritsch, D. Crowd-sourcing the 3D digital reconstructions of lost cultural heritage. 2015 Digit. Herit. 2016, 1, 171-172.

21. Hansen, A.S. Outdoor recreation monitoring in coastal and marine areas-An overview of Nordic experiences and knowledge. Geogr. Tidsskr. J. Geogr. 2016, 116, 110-122. [CrossRef]

22. Bapiri, J.; Esfandiar, K.; Seyfi, S. A photo-elicitation study of the meanings of a cultural heritage site experience: A means-end chain approach. J. Herit. Tour. 2021, 16, 62-78. [CrossRef]

23. Grun, A.; Remondino, F.; Zhang, L. Photogrammetric reconstruction of the Great Buddha of Bamiyan, Afghanistan. Photogramm. Rec. 2004, 19, 177-199. [CrossRef]

24. Baer, N. Conservation notes: Maintenance of outdoor bronze sculpture. Int. J. Mus. Manag. Curatorship 1988, 7, 71-75.

25. Garrod, B. Understanding the relationship between tourism destination imagery and tourist photography. J. Travel Res. 2009, 47, 346-358. [CrossRef]

26. Robinson, M.; Picard, D. Moments, magic and memories: Photographing tourists, tourist photographs and making worlds. In The Framed World, Tourisms, Tourists and Photography; Routledge: Abingdon, UK, 2009; pp. 1-37.

27. Oeldorf-Hirsch, A.; Sundar, S.S. Social and technological motivations for online photo sharing. J. Broadcast. Electron. Media 2016, 60, 624-642. [CrossRef]

28. Wang, R.; Luo, J.; Huang, S.S. Developing an artificial intelligence framework for online destination image photos identification. J. Destin. Mark. Manag. 2020, 18, 100512. [CrossRef]

29. Zhang, K.; Chen, Y.; Lin, Z. Mapping destination images and behavioral patterns from user-generated photos: A computer vision approach. Asia Pac. J. Tour. Res. 2020, 25, 1199-1214. [CrossRef]

30. Manovich, L. Instagram and Contemporary Image. 2017. Available online: http://manovich.net/index.php/projects/instagramand-contemporary-image (accessed on 12 April 2021).

31. Hu, Y.; Manikonda, L.; Kambhampati, S. What we instagram: A first analysis of Instagram photo content and user types. In Proceedings of the 8th International Conference on Weblogs and Social Media, ICWSM, Ann Arbor, MI, USA, 1-4 June 2014; pp. 595-598.

32. Puttilli, M. Everyday geographies in the changing city: Subjective photo-routes in Mandalay, Myanmar. GeoJournal 2020, 8, 1-20. [CrossRef]

33. Falk, M.T.; Hagsten, E. Visitor flows to World Heritage Sites in the era of Instagram. J. Sustain. Tour. 2020, 1-16. [CrossRef]

34. Bakhshi, S.; Shamma, D.A.; Gilbert, E. Faces engage us: Photos with faces attract more likes and comments on Instagram. In Proceedings of the Conference on Human Factors in Computing Systems, Toronto, ON, Canada, 26 April-1 May 2014; pp. 965-974.

35. López-Chao, V.; Lopez-Pena, V. Aesthetical appeal and dissemination of architectural heritage photographs in Instagram. Buildings 2020, 10, 225. [CrossRef]

36. Stylianou-Lambert, T. Tourists with cameras: Reproducing or producing? Ann. Tour. Res. 2012, 39, 1817-1838. [CrossRef]

37. Haldrup, M.; Larsen, J. Material cultures of tourism. Leis. Stud. 2006, 25, 275-289. [CrossRef]

38. Konijn, E.; Sluimer, N.; Mitas, O. Click to share: Patterns in tourist photography and sharing. Int. J. Tour. Res. 2016, 18, 525-535. [CrossRef] 
39. Mackay, K.J.; Couldwell, C.M. Using visitor-employed photography to investigate destination image. J. Travel Res. 2004, 42, 390-396. [CrossRef]

40. Jenkins, O. Photography and travel brochures: The circle of representation. Tour. Geogr. 2003, 5, 305-328. [CrossRef]

41. Gye, L. Picture this: The impact of mobile camera phones on personal photographic practices. Continuum (N.Y.) 2007, 21, 279-288. [CrossRef]

42. Fotis, J.N. The Use of Social Media and Its Impacts on Consumer Behaviour: The Context of Holiday Travel. Ph.D. Thesis, Bournemouth University, Bournemouth, UK, May 2015.

43. Wang, D.; Xiang, Z.; Fesenmaier, D.R. Smartphone use in everyday life and travel. J. Travel Res. 2016, 55, 52-63. [CrossRef]

44. Jung, T.H.; Dieck, M.C.T. Augmented reality, virtual reality and 3D printing for the co-creation of value for the visitor experience at cultural heritage places. J. Place Manag. Dev. 2017, 10, 140-151. [CrossRef]

45. Minazzi, R.; Mauri, A.G. Mobile technologies effects on travel behaviours and experiences: A preliminary analysis. In Information and Communication Technologies in Tourism 2015; Tussyadiah, I., Inversini, A., Eds.; Springer: Cham, Switzerland, 2015.

46. Ghaderi, Z.; Hatamifar, P.; Ghahramani, L. How smartphones enhance local tourism experiences? Asia Pac. J. Tour. Res. 2019, 24, 778-788. [CrossRef]

47. Huang, C.D.; Goo, J.; Nam, K.; Yoo, C.W. Smart tourism technologies in travel planning: The role of exploration and exploitation. Inf. Manag. 2017, 54, 757-770. [CrossRef]

48. Stogner, M.B. The media-enhanced museum experience: Debating the use of media technology in cultural exhibitions. Curator Mus. J. 2009, 52, 385-397. [CrossRef]

49. Stein, R. Chiming in on museums and participatory culture. Curator Mus. J. 2012, 55, 215-226. [CrossRef]

50. Jarrier, E.; Bourgeon-Renault, D. Impact of mediation devices on the museum visit experience and on visitors' behavioural intentions. Int. J. Arts Manag. 2012, 15, 18-29.

51. Buffa, F. Young tourists and sustainability. Profiles, attitudes, and implications for destination strategies. Sustainability 2015, 7 , 14042-14062. [CrossRef]

52. Femenia-Serra, F.; Perles-Ribes, J.F.; Ivars-Baidal, J.A. Smart destinations and tech-savvy millennial tourists: Hype versus reality. Tour. Rev. 2019, 74, 63-81. [CrossRef]

53. Xiang, Z.; Magnini, V.P.; Fesenmaier, D.R. Information technology and consumer behavior in travel and tourism: Insights from travel planning using the internet. J. Retail. Consum. Serv. 2015, 22, 244-249. [CrossRef]

54. Gajdošík, T. Smart tourists as a profiling market segment: Implications for DMOs. Tour. Econ. 2020, 26, 1042-1062. [CrossRef]

55. Buhalis, D.; Amaranggana, A. Smart tourism destinations enhancing tourism experience through personalisation of services. Inf. Commun. Technol. Tour. 2015, 2015, 377-389. [CrossRef]

56. Lin, S.Y.; Juan, P.J.; Lin, S.W. A tam framework to evaluate the effect of smartphone application on tourism information search behavior of foreign independent travelers. Sustainability 2020, 12, 9366. [CrossRef]

57. Yang, S.; Lu, Y.; Gupta, S.; Cao, Y. Does context matter? The impact of use context on mobile internet adoption. Int. J. Hum. Comput. Interact. 2012, 28, 530-541. [CrossRef]

58. Peng, K.-F.; Chen, Y.; Wen, K.-W. Brand relationship, consumption values and branded app adoption. Ind. Manag. Data Syst. 2014, 114, 1131-1143. [CrossRef]

59. Yoo, C.; Kwon, S.; Na, H.; Chang, B. Factors affecting the adoption of gamified smart tourism applications: An integrative approach. Sustainability 2017, 9, 2162. [CrossRef]

60. Gupta, A.; Dogra, N.; George, B. What determines tourist adoption of smartphone apps?: An analysis based on the UTAUT-2 framework. J. Hosp. Tour. Technol. 2018, 9, 48-62. [CrossRef]

61. Kapoor, K.K.; Dwivedi, Y.K.; Williams, M.D. Conceptualizing the role of innovation: Attributes for examining consumer adoption of mobile innovations. Mark. Rev. 2014, 14, 405-428. [CrossRef]

62. Taylor, D.G.; Levin, M. Predicting mobile app usage for purchasing and information-sharing. Int. J. Retail. Distrib. Manag. 2014, 42, 759-774. [CrossRef]

63. Schierz, P.G.; Schilke, O.; Wirtz, B.W. Understanding consumer acceptance of mobile payment services: An empirical analysis. Electron. Commer. Res. Appl. 2010, 9, 209-216. [CrossRef]

64. Cairns, P. Can games be more than fun? In Funology 2: From Usability to Enjoyment, 2nd ed.; Blythe, M., Monk, A., Eds.; Springer: Cham, Switzerland, 2018; pp. 33-46.

65. Deterding, S.; Dixon, D.; Khaled, R.; Nacke, L. From game design elements to gamefulness: Defining 'gamification'. In Proceedings of the 15th International Academic MindTrek Conference: Envisioning Future Media Environments, Taampere, Finland, 28-30 September 2011.

66. Seaborn, K.; Fels, D.I. Gamification in theory and action: A survey. Int. J. Hum. Comput. Stud. 2015, 74, 14-31. [CrossRef]

67. Lu, H.-P.; Ho, H.-C. Exploring the impact of gamification on users' engagement for sustainable development: A case study in brand applications. Sustainability 2020, 12, 4169. [CrossRef]

68. Wu, X.; Liu, S.; Shukla, A. Serious games as an engaging medium on building energy consumption: A review of trends, categories and approaches. Sustainability 2020, 12, 8508. [CrossRef]

69. Sajinčič, N.; Sandak, A.; Starčič, A.I. Gamification in education and learning. In Proceedings of the International Conference EDUvision, Ljubljana, Slovenia, 28-30 November 2019; pp. 993-1001. 
70. Tang, J.; Prestopnik, N.R. Exploring the impact of game framing and task framing on user participation in citizen science projects. Aslib J. Inf. Manag. 2019, 71, 260-280. [CrossRef]

71. Gómez-Ruiz, M.-L.; Morales-Yago, F.-J.; Lázaro-Torres, M.-L. Outdoor education, the enhancement and sustainability of cultural heritage: Medieval Madrid. Sustainability 2021, 13, 1106. [CrossRef]

72. Negruşa, A.L.; Toader, V.; Sofică, A.; Tutunea, M.F.; Rus, R.V. Exploring gamification techniques and applications for sustainable tourism. Sustainability 2015, 7, 11160-11189. [CrossRef]

73. Pokémon Go. ActivePlayer.io-The Game Statistics Authority. Available online: https://activeplayer.io/pokemon-go/ (accessed on 15 April 2021).

74. Geocaching HQ. 2020 in the Rearview ... We Mean, Year in Review. Available online: https://www.geocaching.com/blog/2021 /01/2020-in-the-rearview- \includegraphics[scale=1]\{sustainability-1214975-i001.pdf\}-we-mean-year-in-review/ (accessed on 15 April 2021).

75. Alha, K.; Koskinen, E.; Paavilainen, J.; Hamari, J. Why do people play location-based augmented reality games: A study on Pokémon GO. Comput. Hum. Behav. 2019, 93, 114-122. [CrossRef]

76. Rasche, P.W.V.; Schlomann, A.; Mertens, A.W. Who is still playing Pokémon Go? A web-based survey. JMIR Serious Games 2017, 5, 1-14. [CrossRef]

77. Orosz, G.; Zsila, Á.; Vallerand, R.J.; Böthe, B. On the determinants and outcomes of passion for playing Pokémon Go. Front. Psychol. 2018, 9, 1-8. [CrossRef] [PubMed]

78. Yang, C.-C.; Liu, D. Motives matter: Motives for playing Pokémon Go and implications for well-being. Cyberpsychol. Behav. Soc. Netw. 2017, 20, 52-57. [CrossRef]

79. Hamari, J.; Malik, A.; Koski, J.; Johri, A. Uses and gratifications of Pokémon Go: Why do people play mobile location-based augmented reality games? Int. J. Hum. Comput. Interact. 2019, 35, 804-819. [CrossRef]

80. O'Hara, K. Understanding geocaching practices and motivations. In Proceedings of the Twenty-Sixth Annual CHI Conference on Human Factors in Computing Systems-CHI, Florence, Italy, 5-10 April 2008; pp. 1177-1186.

81. Rosier, J.L.; Yu, A.H.-C. Exploring the effects of geocaching on understanding natural resources and history. In Proceedings of the Northeast Recreation Research Symposium, New York, NY, USA, 10-12 April 2011; pp. 1-5.

82. Mehrbod, A.; Mehrbod, N.; Grilo, A.; Vasconcelos, C.; Silva, J.L. Gamification in supported geocaching tours. In Proceedings of the International Conference on Engineering, Technology and Innovation Management beyond 2020 New Challenges, New Approaches ICE/ITMC, Madeira Island, Portugal, 27-29 June 2017; pp. 1419-1423.

83. McGookin, D.; Tahiroğlu, K.; Vaittinen, T.; Kytö, M.; Monastero, B.; Vasquez, J.C. Investigating tangential access for location-based digital cultural heritage applications. Int. J. Hum. Comput. Stud. 2019, 122, 196-210. [CrossRef]

84. Morgan, D.L. Focus groups. Annu. Rev. Sociol. 1996, 22, 129-152. [CrossRef]

85. Stewart, D.W.; Shamdasani, P.N.; Rook, D.W.R. Analyzing focus group data. In Focus Groups: Theory and Practice; Sage: London, UK, 2007; pp. 109-133.

86. Slavec, A.; Starman, V.; Sajinčič, N. Use of Mobile Applications for Visits of Cultural Heritage Monuments [Data file]; University of Ljubljana, Slovenian Social Science Data Archives: Ljubljana, Slovenia, 2020. [CrossRef]

87. Čermuta, L. Two-Thirds of Slovenian Residents Went on Private Trips In 2019. Republic of Slovenia Statistical Office. 2020. Available online: https:/ / www.stat.si/StatWeb/en/News/Index/8874 (accessed on 12 April 2021). 